\title{
Manuseio da deiscência do esterno no pós-operatório de cirurgia cardíaca
}

Roberto Latorre MARQUES ${ }^{\star}$, Antoninho S. ARNONI*, Jarbas J. DINKHUYSEN*, Paulo CHACCUR*, Camilo ABDULMASSIH NETO*, Luiz Carlos Bento de SOUZA*, Paulo P. PAULISTA*

RBCCV 44205-116

\begin{abstract}
MARQUES, R. L.; ARNONI, A. S.; DINKHUYSEN, J. J.; ABDULMASSIH NETO, C.; SOUZA, L. C. B.; PAULISTA, P. P. - Manuseio da deiscência do esterno no pós-operatório de cirurgia cardíaca. Rev. Bras. Cir. Cardiovasc., 5(2): 125-136, 1990.

RESUMO: No período de dezembro de 1987 a dezembro de 1989, 906 pacientes foram submetidos a cirurgia cardiaca com circulaçāo extracorpórea, no Instituto Dante Pazzanese de Cardiologia, sendo $43 \%$ coronarianos, $37 \%$ valvares, $17 \%$ congênitos e $3 \%$ outros. Dentre eles, observou-se, na fase intra-hospitalar de pós-operatório, a ocorrência de 19 casos de deiscência parcial ou total da toracotomia mediana $(2 \%)$, que ocorreu, em média, ao redor da 1: semana de pós-operatório, tendo sido a reintervenção cirúrgica por volta da 3: semana. As culturas mostraram predomínio de germes gram positivos e poucos casos de gram negativos e fungos. Em apenas um caso não foi isolado qualquer agente infeccioso. Neste grupo de pacientes, constatou-se a presença de fatores predominantes, tais como diabetes, obesidade, doença pulmonar obstrutiva crônica (DPOC) e tempo prolongado de cirurgia (média de 6 horas). Houve predomínio de pacientes adultos, cujas idades variaram de 40 a 67 anos, média de 53 anos (89\%). Constatou-se que, em $84 \%$ dos pacientes, a artéria mamária interna foi utilizada como enxerto na revascularização cirúrgica do miocárdio. Além das medidas gerais de terapêutica local e sistêmica com antibióticos específicos, visando ao combate dos agentes infecciosos e à conseqüente esterilização da ferida, os pacientes eram conduzidos à sala de operação, procedendo-se à limpeza e desbridamento dos planos cirúrgicos, incluindo o esterno, deixando-se, em alguns casos, irrigação contínua com solução de povidine. Em dois pacientes foi realizada rotação de retalho miocutâneo, devido à refratariedade ao tratamento. De cinco casos de mediastinite, três faleceram por falência de múltiplos órgãos e sepsis. O grupo restante apresentou boa evolução, tendo obtido alta hospitalar após a 3: semana da reintervenção, com boa cicatrização da ferida operatória.
\end{abstract}

DESCRITORES: deiscência de esterno, cirurgia.

\section{INTRODUÇĀO}

A esternotomia mediana foi introduzida por JULIAN et alii ${ }^{17}$, em 1957 , sendo a incisão de escolha para a maioria dos procedimentos cirúrgicos, envolvendo o mediastino, coração e grandes vasos da base. Embora as complicações da ferida, após a esternotomia, sejam raras, a infecção é ameaçadora pela possibilidade de extensão, causando sepsis e envolvimento dos enxertos aorto-coronarianos, da aortotomia, das incisões cardia- cas e das próteses. O tratamento com a técnica de desbridamento e fechamento do esterno, seguindo-se de acompanhamento até a granulação dos demais tecidos, foi utilizada até 1963. A técnica de desbridamento esternal, irrigação mediastinal fechada contínua com antibiiticos e drenagem, foi utilizada por SCHUMAKER \& MANDELBAUM $^{34}$, em 1963, melhorando significativamente o prognóstico dos pacientes. BRYANT et alii ${ }^{5}$, em 1969 , apresentam cinco casos de mediastinite, tratados com irrigaçāo fechada contínua com antibióticos. ENGEL-

\footnotetext{
Trabalho realizado no Instituto Dante Pazzanese de Cardiologia. São Paulo, SP, Brasil.

Recebido para publicação em 20 de fevereiro, 1990.

* Do Instituto Dante Pazzanese de Cardiologia.

Endereço para separatas: Roberto Latorre Marques. Av. Dr. Dante Pazzanese, 500. Seçâo de Cirurgia Humana. 04531 São Paulo, SP, Brasil.
} 
MARQUES, R. L.; ARNONI, A. S.; DINKHUYSEN, J. J.; ABDULMASSIH NETO, C.; SOUZA, L. C. B.; PAULISTA, P. P. - ManUSEio da deiscência do esterno no pós-operatório de cirurgia cardiaca. Rev. Bras. Cir. Cardiovasc., 5(2): 125-136, 1990.

MAN et alii ${ }^{10}$ sugerem fechamento da pele e irrigaçăo contínua do tecido com antibióticos.

Em 1974, THURER et alii ${ }^{42}$ relatam bons resultados com desbridamento esternal e irrigação mediastinal contínua fechada com soluçāo de povidine e drenagem, retardando o fechamento dos demais tecidos. Seguem-se, logo após, vários trabalhos, como o de JURKIEWICZ et alii ${ }^{18}$, NEALE et alii $^{26}$ e ARNOLD \& PAIROLERO ${ }^{2}$ para o tratamento dos defeitos esternais.

A finalidade deste trabalho é mostrar o papel desempenhado pela equipe cirúrgica, no tratamento da deiscência de esterno e no manuseio das complicações, que podem surgir no decurso de uma infecçāo esternal.

\section{CASUÍSTICA E MÉTODOS}

No Instituto Dante Pazzanese de Cardiologia, de dezembro de 1987 a dezembro de 1989, 906 pacientes foram submetidos a cirurgia cardíaca com circulação extracorpórea, sendo $43 \%$ coronarianos, $37 \%$ valvares, $17 \%$ congênitos e $3 \%$ outras lesōes. Ocorreram 19 casos de deiscência da toracotomia mediana ( $2 \%)$. Dezesseis pacientes eram coronarianos, dois pacientes valvares e um congênito. Deiscência total apareceu em 16 pacientes e parcial em três. Foi considerada deiscência total quando todo o esterno encontrava-se instável e parcial quando somente parte dele estava comprometido. A maioria dos pacientes ${ }^{16}$ era do sexo masculino e apenas três do sexo feminino. Dos pacientes que se submeteram à revascularizaçāo do miocárdio, $84 \%$ tiveram a artéria mamária interna esquerda dissecada para ser empregada como enxerto. Os fatores de risco, observados para os coronarianos, foram: dissecção de mamária, obesidade, diabetes, doença pulmonar obstrutiva crônica (DPOC); para os valvares, reoperação e DPOC. No grupo de congênitos, não foi idenficado qualquer fator de risco (um caso). O tempo médio de cirurgia foi de seis horas e o tempo de permanência na UTI, três dias. Tivemos mais de um paciente que apresentou dois ou mais fatores de risco.

Do ponto de vista clínico, o aspecto da ferida operatória com aparecimento de rubor, hiperemia, coleção purulenta e instabilidade do esterno denunciaram o quadro infeccioso, por volta da 1: semana de pós-operatório. Acompanhou a evolução clínica dos pacientes febre persistente, queda do estado geral, anorexia e alteraçāo laboratorial com leucocitose e desvio para a esquerda. As hemoculturas, cultura de secreção e antibiograma tiveram um papel importante na orientação do tratamento quimioterápico específico ao agente infeccioso, sendo necessário, em todos os doentes, a associação antibiótica pela alta incidência de poli-infecção. A radiografia de tórax e a fistulografia foram úteis na avaliação da extensão do quadro infeccioso.

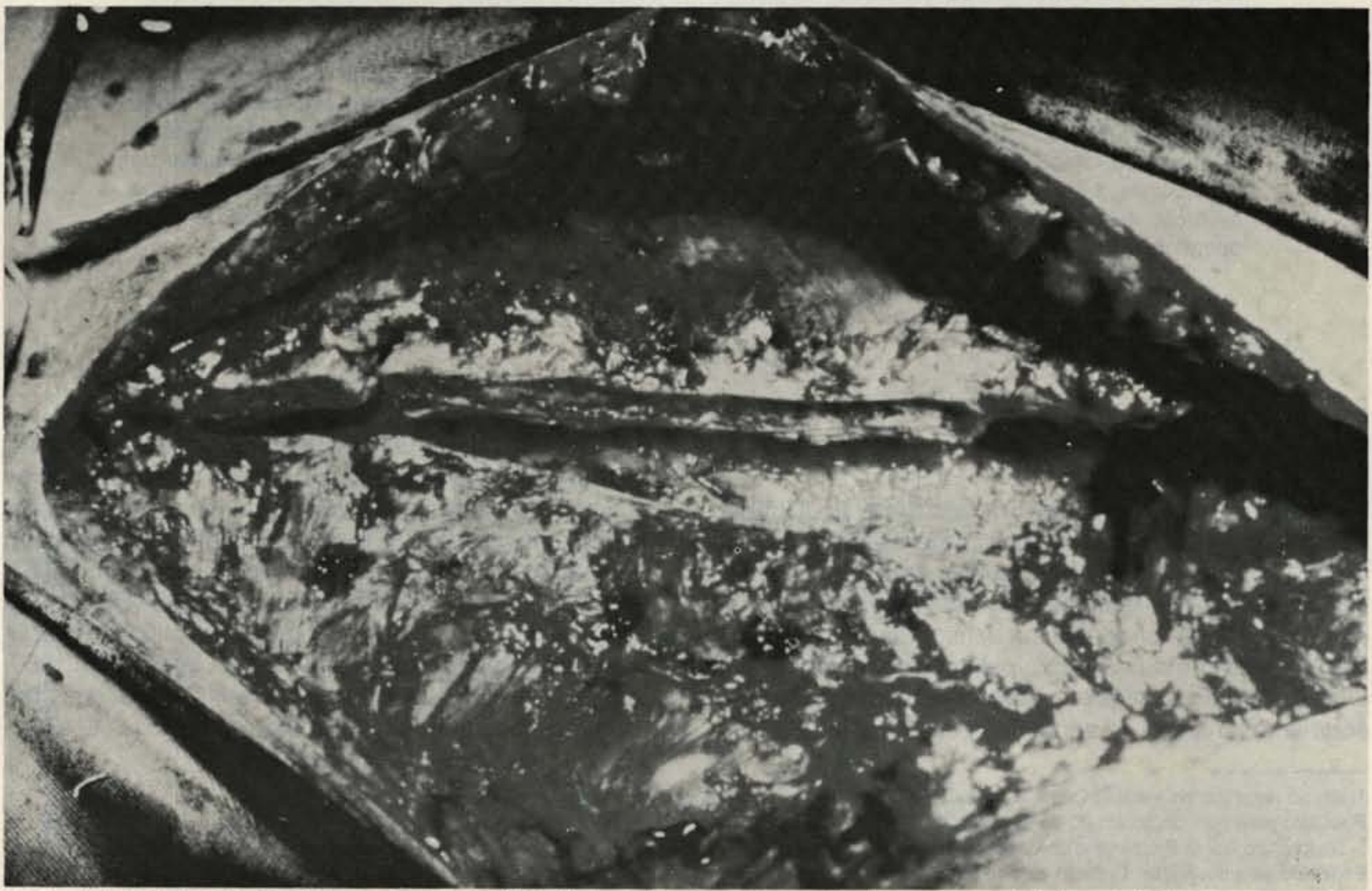

Fig. 1 - Esterno deiscente, com fratura a nivel do manúbrio. Todos os fios de aço foram retirados e os planos cirúrgicos desbridados. 


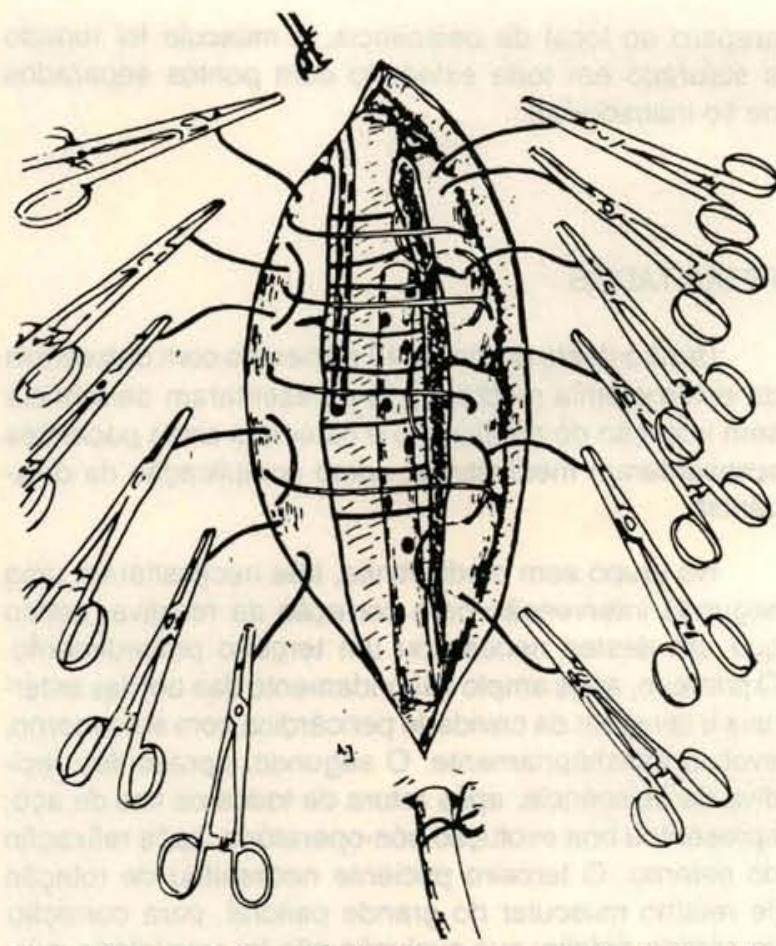

Fig. 2 - Aspecto da disposiçăo dos drenos no mediastino. Reforço bilateral do esterno com fios de aço passados nos espaços intercostais (Verkkala et alii. Scand. J. Thorac. Cardiovasc., Surg., 20: 203-207, 1986.).
O papel do cirurgião assume importância, através de curativos diários (dois a três) e drenagem das lojas com coleção purulenta. Após a estabilização clínica do paciente, com melhora do suporte nutricional, antibióticoterapia, curativos diários e negativação das culturas, os pacientes são conduzidos à sala de operação.

O procedimento depende da extensāo e da gravidade do processo.

Nas situações sem mediastinite, com os fios de aço frouxos, instabilizando o esterno, era feita a refixação dos fios, seguida de ampla limpeza dos tecidos musculares, subcutâneo e pele, com ressecção do tecido fibrótico e posterior fechamento por planos, se possível. Quando necessário, utilizamos pontos subtotais.

Nos casos sem mediastinite, com esterno totalmente solto, por lesão do osso pelo fio ou por este fraturado, faziamos a retirada desses fios (Figura 1), com posterior tratamento do esterno, com retirada de pequena camada de osso e de todo tecido necrótico do periósteo e da própria medula óssea. Terminada esta fase, o esterno era fixado com novos fios de aço, passados de preferência em forma de $X$ para melhor coaptação das bordas, procedendo-se, depois, a limpeza e sutura das camadas muscular, subcutânea e pele.

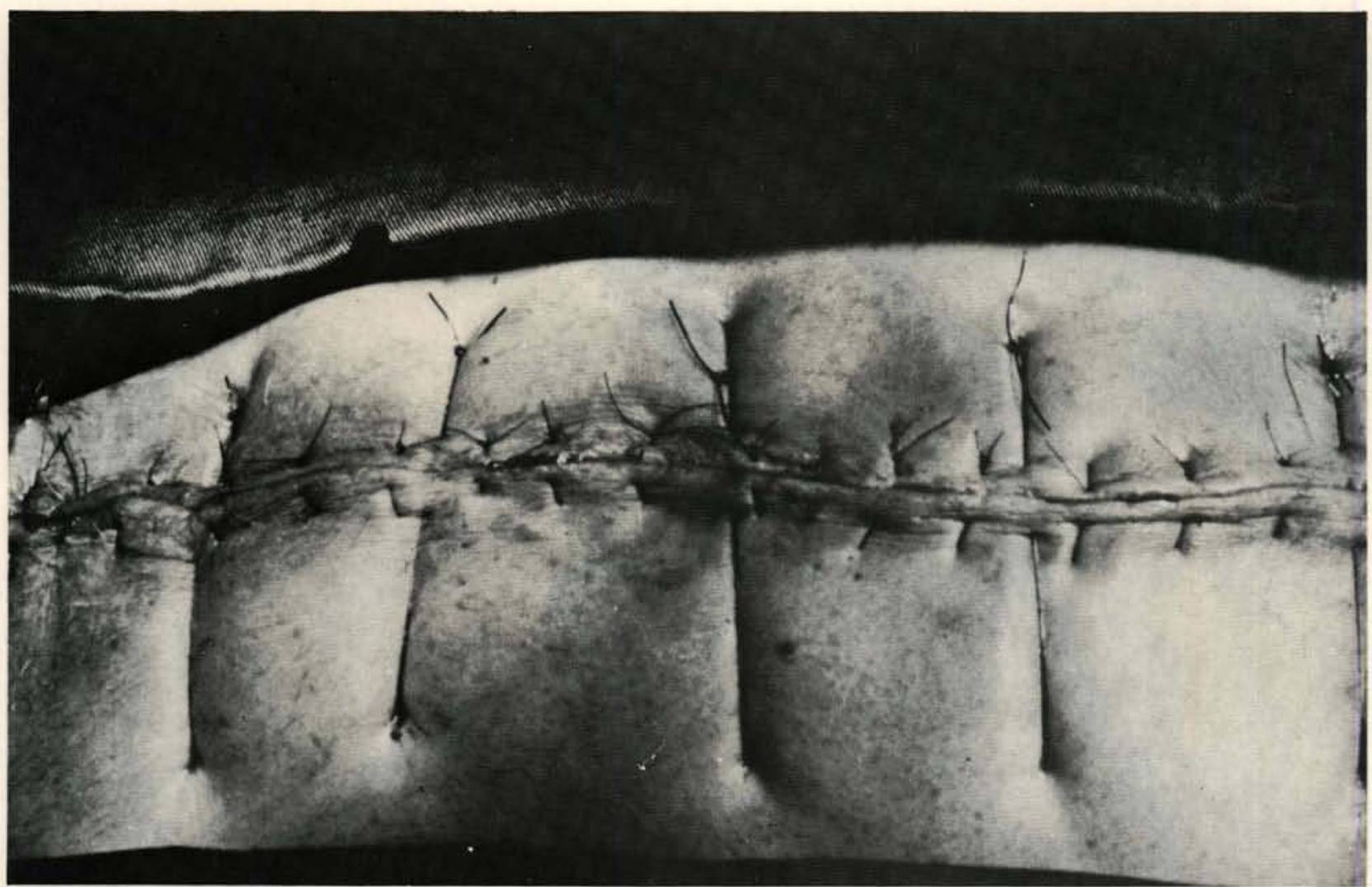

Fig. 3 - Aspecto final do fechamento com a disposição dos pontos subtotais com Prolene 2. 
MARQUES, R. L.; ARNONI, A. S.; DINKHUYSEN, J. J.; ABDULMASSIH NETO, C.; SOUZA, L. C. B.; PAULISTA, P. P. - ManUSEio da deiscência do esterno no pós-operatório de cirurgia cardiaca. Rev. Bras. Cir. Cardiovasc., 5(2): 125-136, 1990.

Já nos casos com mediastinite, além do descrito anteriormente, a cavidade pericárdica era lavada com soro morno, retirando toda a fibrina sobre o coração, e colocaçāo de dois drenos, sendo um deles posicionado sobre a borda superior da incisão para infusāo de solução de povidine a $0,5 \%$ e outro pela borda inferior, para drenagem da solução infundida e do material resultante da lavagem pericárdica (Figura 2).

Os drenos são retirados após a negativação das culturas do material recolhido no dreno inferior. Primeiramente, é retirado o dreno superior e, 24 a 48 horas depois, o inferior.

Nos indivíduos obesos, foi deixado um dreno tipo "port-o-vac" em subcutâneo, que, geralmente, é retirado no 2 : dia após a reintervenção. Quatro ou mais pontos subtotais de contençāo com Prolene n: 2 foram deixados em todos os doentes (Figura 3).

Nos casos em que houve refratariedade à técnica descrita, procedeu-se à rotação de retalho miocutâneo (reto abdominal e/ou grande peitoral). Em um paciente foi utilizado o reto abdominal (Figuras 4 e 5) e o outro, o grande peitoral e o reto abdominal em um segundo tempo. O grande peitoral foi dissecado do gradil costal em uma pequena extensão, preservando-se o pedículo, para que pudesse ser rodado sobre a borda esternal oposta. O terço superior do reto abdominal também foi dissecado, preservando-se o pedículo vascular. Após preparo do local da deiscência, o músculo foi rodado e suturado em toda extensão com pontos separados de fio inabsorvível.

\section{RESULTADOS}

Dentro deste grupo de 19 pacientes com deiscência da esternotomia mediana, 14 apresentaram deiscência sem infecção do mediastino e os outros cinco pacientes apresentaram mediastinite, como complicação da deiscência.

No grupo sem mediastinite, três necessitaram uma segunda intervenção para correção da recidiva, sendo que um destes necessitou um terceiro procedimento. O primeiro, após amplo desbridamento das bordas esternais e lavagem da cavidade pericárdica com soro morno, evoluiu satisfatoriamente. O segundo, apresentou recidiva da deiscência, após rotura de todos os fios de aço; apresentou boa evolução pós-operatória, após refixação do esterno. O terceiro paciente necessitou de rotação de retalho muscular do grande peitoral, para correçāo do grande defeito; sua evolução nāo foi satisfatória, surgindo, no pós-operatório, recidiva da deiscência. Foi encaminhado a uma terceira cirurgia, para rotação do músculo reto-abdominal. Após esse procedimento, evoluiu satisfatoriamente.

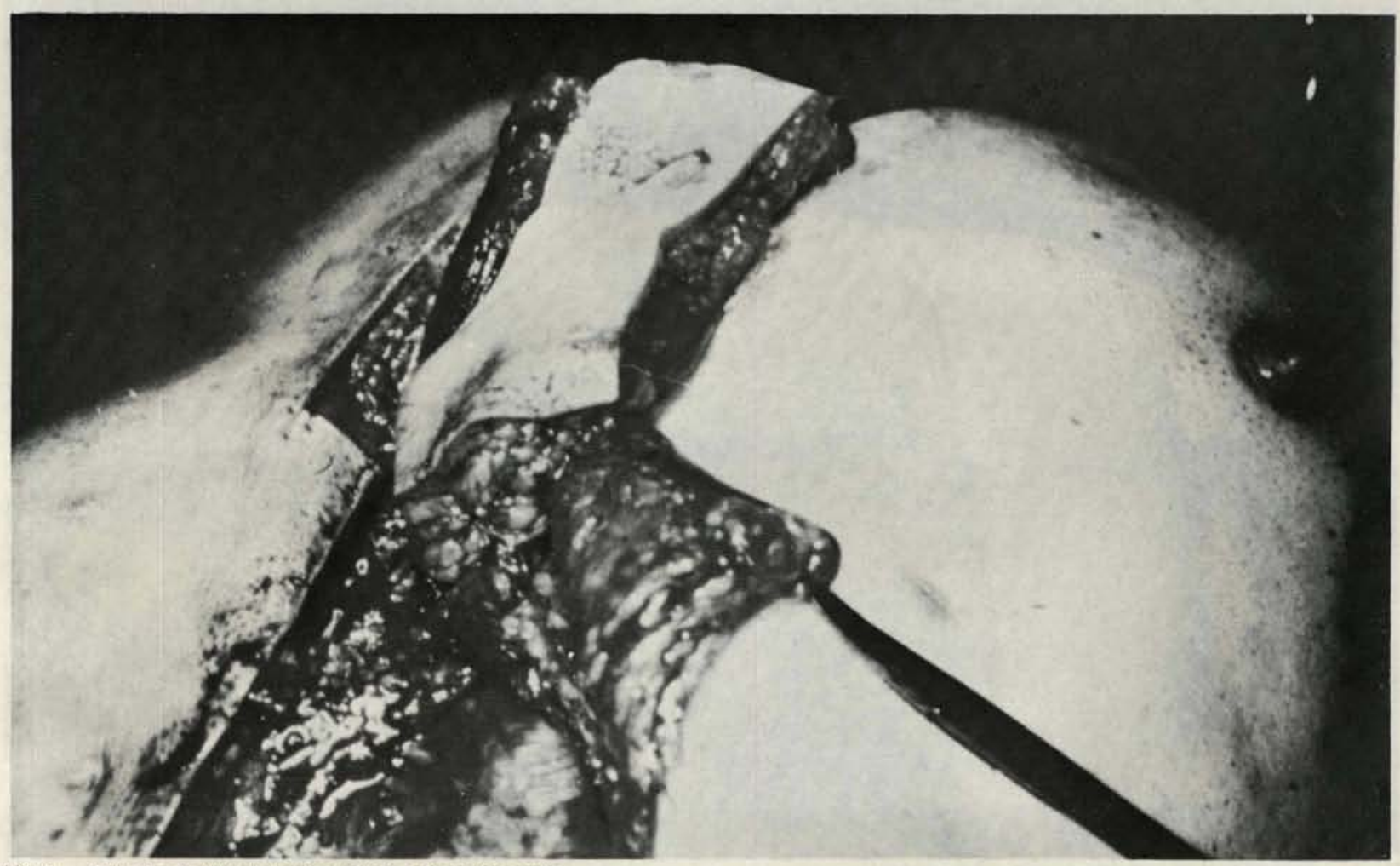

Fig. 4 - Rotaçấo do reto abdominal sobre a área deiscente. 
MARQUES, R. L.; ARNONI, A. S.; DINKHUYSEN, J. J.; ABDULMASSIH NETO, C.; SOUZA, L. C. B.; PAULISTA, P. P. - ManUSeio da deiscência do esterno no pós-operatório de cirurgia cardiaca. Rev. Bras. Cir. Cardiovasc., 5(2): 125-136, 1990.

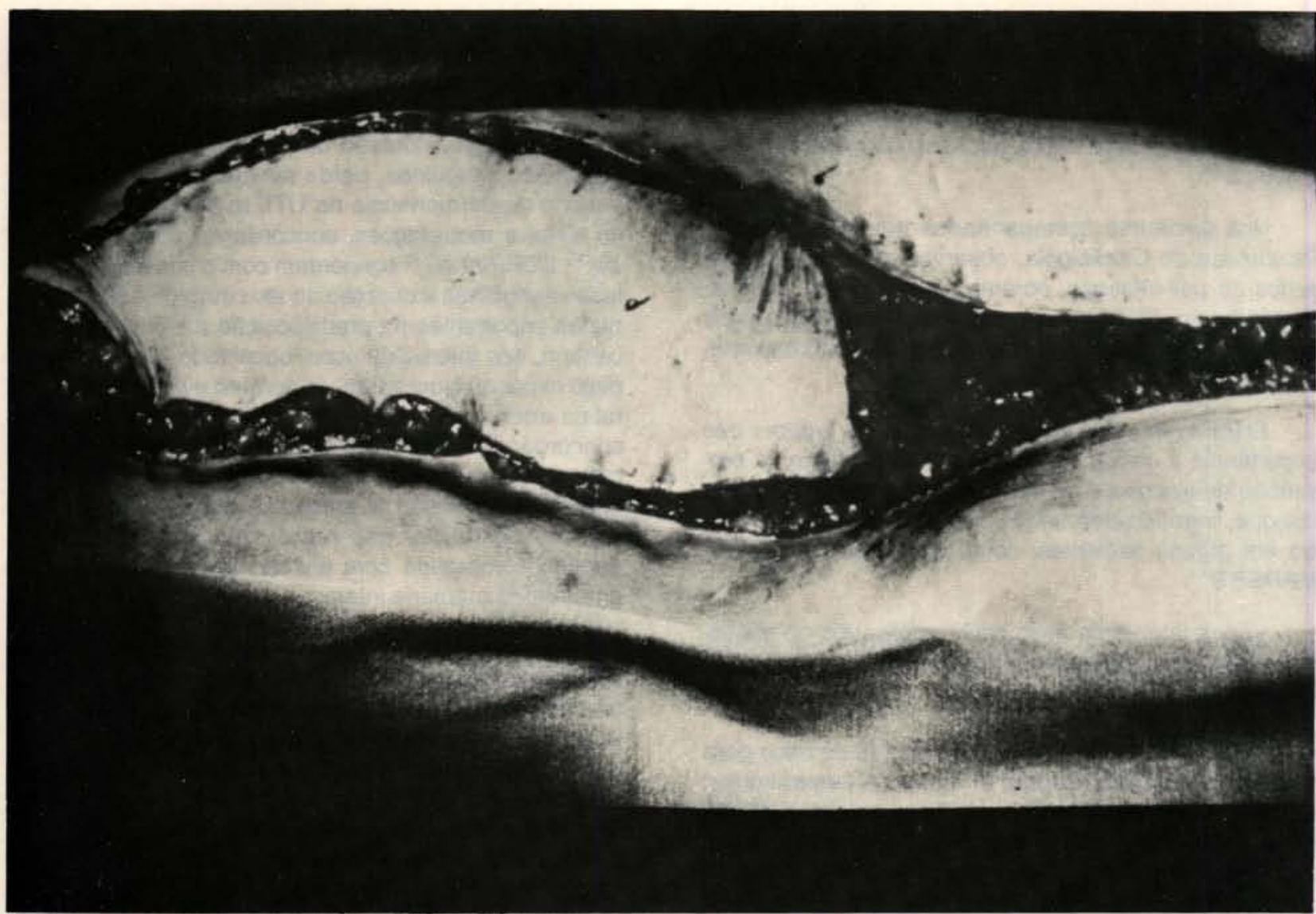

Fig. 5 - Disposição da musculatura abdominal após rotação do retalho.

No grupo com mediastinite, todos os cinco pacientes, após desbridamento das bordas esternais, lavagem da cavidade pericárdica, retirada de todo material necrótico, foram submetidos a irrigação contínua com solução de povidine a $0,5 \%$. Tivemos três óbitos, dois em vigência de insuficiência renal aguda e sepsis e outro, após convulsões subentrantes e parada cardiorrespiratória. Um dos pacientes que não foi a óbito retornou ao Serviço com fístulas esternais, um ano mais tarde, sendo encaminhado à cirurgia para curetagem de todo o trajeto fistuloso, com boa evolução. O outro, após cura da mediastinite com irrigaçāo, apresentou recidiva da deiscência, com novo quadro de mediastinite. Foi encaminhado à cirurgia para rotação do reto-abdominal, obtendo bom resultado no pós-operatório.

\section{DISCUSSÃO}

A esternotomia mediana, introduzida, inicialmente, por JULIAN et alii ${ }^{17}$, em 1957 , é a via de acesso de escolha para a maioria dos procedimentos, envolvendo o coração, os grandes vasos da base e o mediastino. As complicações, embora infreqüentes, são sérias. A deiscência de esterno apresenta alta morbi-mortalidade, principalmente, quando acompanhada de mediastinite.
A conduta da equipe cirúrgica tem como objetivo avaliar o paciente na fase aguda da infecção, para melhoria do prognóstico cirúrgico.

A pergunta mais importante é se as complicações da esternotomia mediana estão na dependência da infecção, ou da instabilidade esternal. COOLEY ${ }^{8}$ acredita que a deiscência precede a infecção.

Existem vários tipos de complicaçōes, que podem ocorrer no pós-operatório de cirurgia cardiaca, quando a abordagem se faz via toracotomia mediana. SERRY et alii ${ }^{36}$ dão, como principais complicaçōes, a drenagem serosangüinolenta com esterno estável, a instabilidade esternal com ou sem drenagem estéril, a deiscência de esterno sem evidência de mediastinite, a infecção tecidual superficial, a infecção do tecido subcutâneo associado à instabilidade do esterno e a comunicação com o espaço retroesternal associada à mediastinite com ou sem separação do esterno ou da pele. HARJULA \& JARVINEN ${ }^{13}$ concordam com Serry, frisando, como principais complicações da esternotomia mediana, a pericardite purulenta e a mediastinite.

De acordo com VERKKALA \& JARVINEN ${ }^{44}$, a mediastinite pode, como conseqüência, levar à osteomielite crônica de esterno. A incidência de osteomielite de ester- 
MARQUES, R. L.; ARNONI, A. S.; DINKHUYSEN, J. J.; ABDULMASSIH NETO, C.; SOUZA, L. C. B.; PAULISTA, P. P. - ManUSeio da deiscência do esterno no pós-operatório de cirurgia cardiaca. Rev. Bras. Cir. Cardiovasc., 5(2): 125-136, 1990.

no e de costocondrite não mudou com a era antibiótica e com os novos métodos de tratamento. A infecçāo pode ser indolente e ocorrer na ausência de mediastinite, freqüentemente envolvendo microrganismos antibióticoresistentes, que, raramente, causam osteomielite hematogênica ${ }^{45}$.

Nos pacientes acompanhados no Instituto Dante Pazzanese de Cardiologia, observamos sempre a presença de poli-infecção, porém os germes que prevaleceram foram Staphylococcus aureus e Staphylcoccus epidermidis, concordando com outros trabalhos da literatura 24,31 .

SHAFIR et alii ${ }^{37}$ afirmam que poucos autores dāo importância a uma precisa osteotomia mediana na prevenção de fraturas e de exposição das cartilagens costais que, segundo eles, seria uma das causas de deiscência em alguns pacientes, como concordam TABER \& MADERS ${ }^{41}$.

Vários fatores de risco estão implicados no desenvolvimento de deiscência de esterno, no pós-operatório de cirurgia cardíaca.

NEWMAN et alii ${ }^{27}$ dividem os fatores de risco para mediastinite em três etapas: a) fatores pré-operatórios: história de doença pulmonar obstrutiva crônica (DPOC), esternotomia prévia, piúria, fração de ejeção baixa, pressão diastóliça do ventrículo esquerdo elevada; b) fatores intra-operatórios: cirurgia valvar ou de aneurisma de aorta, tempo de perfusâo prolongado, reentrada em perfusão e duração do ato cirúrgico; c) fatores pós-operatórios: hemorragia, ressuscitação cardiopulmonar no pós-operatório imediato e ventilação mecânica prolongada ( $>48 \mathrm{~h}$ ). Três destes fatores foram encontrados nos pacientes que desenvolveram mediastinite: duração prolongada da cirurgia, DPOC e ventilação mecânica prolongada. Para os autores, os fatores intra-operatórios foram os que tiveram maior correlação com os casos de mediastinite.

SARR et alii $^{33}$ incluem, como fatores de risco, a perfusão cardiopulmonar, por causar alteraçōes nas defesas orgânicas, afetando a função fagocítica, assim como os sistemas de imunidade celular e humoral. Uma diminuiçăo dos fatores do complemento e dos niveis de imunoglobulina surge, imediatamente após a perfusão e durante os primeiros sete dias de pós-operatório.

JOHNSON et alii ${ }^{16}$ destacam o uso de corticóides como fator de risco importante para essa complicação. SARR et alii ${ }^{33}$ citam a hemorragia pós-operatória com formação de hematoma mediastinal como a maior complicação, que levaria a um risco elevado de infecção.

OTTINO et alii ${ }^{30}$ analisam 14 fatores de risco em 2579 procedimentos cirúrgicos, relacionando-os com o aparecimento dessa complicação. Idade, sexo, tipo de antibiótico profilático utilizado, motivo da indicação cirúrgica (urgência ou eletiva) e duração pós-operatória da ventilação mecânica não tiveram associação significativa com predisposição à infecção. Associação importante foi observada entre infecção e cirurgia cardiaca prévia, intervalo entre admissão hospitalar e cirurgia, duração do ato cirúrgico, duração da perfusão cardiopulmonar, transfusāo sangüinea, perda sangüinea pós-operatória, período de permanência na UTI, re-exploração recente do tórax e reoperaçōes, concordando com SERRY et alii $^{36}$. LOPP et alii ${ }^{22}$ concordam com o fato de que transfusão sangüinea e duração do ato cirúrgico representam dados importantes na predisposiçāo à infecção. Acrescentam, aos fatores de risco, obesidade (definida como peso maior ou igual a $20 \%$ do normal) e dissecção bilateral da artéria mamária interna na presença de diabetes, concordando com FERNANDO et alii ${ }^{11}$, desenvolvendo necrose avascular de esterno. De acordo com LOOP et alii ${ }^{22}$, a dissecção de ambas as mamárias em pacientes nāo diabéticos não representa importante risco, quando comparada com enxerto somente de veia ou uma artéria mamária interna.

Outros autores citam a dissecção de apenas uma artéria mamária como fator de risco importante, com precário suporte sangüíneo para o esterno e conseqüente desenvolvimento de deiscência ${ }^{45}$. ARNOLD ${ }^{1}$ conclui que a artéria mamária interna é o único suprimento arterial do esterno, sendo assim, a utilização de uma mamária não interfere com o suprimento sangüineo do esterno, porém ambas as mamárias, quando usadas na revascularização cirúrgica do miocárdio, prejudicam o suprimento arterial deste osso. HARJULA \& JARVINEN ${ }^{13}$ encontraram, em um grupo de pacientes estudados, obesidade, doença pulmonar obstrutiva crônica, diabete melito, volume de transfusão sangüinea superior a 10 unidades, complicações pulmonares (atelectasia, edema agudo dos pulmões, ou suporte ventilatório superior a dois dias), síndrome de baixo débito cardiaco (infusāo de dopamina superior a um dia, uso de balāo intra-aórtico e massagem cardiaca externa), infecção de partes moles e fragilidade óssea. A irradiação prévia do mediastino foi realizada com freqüência em um número significativo de pacientes, que apresentaram deiscência da esternotomia mediana ${ }^{31}$.

SIRIVELLA et alii ${ }^{38}$ também acrescentam a estes fatores de risco, irradiação mediastinal prévia. A traqueostomia, como coadjuvante para o desenvolvimento de infecção mediastinal, também foi considerada. No Instituto Dante Pazzanese de Cardiologia, não foram observados casos de mediastinite em pacientes traqueostomizados. Os pacientes submetidos a este tipo de abordagem cirúrgica para ventilação mecânica estẫo sujeitos a contaminação do mediastino por secreção do trato respiratório superior, BRYANT et alii ${ }^{5}$ acham que a traqueostomia tenha relação com a infecção esternal.

THURER et alii ${ }^{42}$ protelam a indicação de traqueostomia em crianças; a intubação nasotraqueal é preferida à traqueostomia e foi utilizada quando o suporte ventilatório foi necessário. 
MARQUES, R. L.; ARNONI, A. S.; DINKHUYSEN, J. J.; ABDULMASSIH NETO, C.; SOUZA, L. C. B.; PAULISTA, P. P. - ManUseio da deiscência do esterno no pós-operatório de cirurgia cardiaca. Rev. Bras. Cir. Cardiovasc., 5(2): 125-136, 1990.

Normalmente, os pacientes traqueostomizados estão seriamente enfermos, portanto já apresentam outros fatores predisponentes para desenvolvimento de complicações esternais ${ }^{36}$.

CHEUNG et alii ${ }^{7}$ observam uma taxa significantemente elevada de infecção esternal em pacientes submetidos a cirurgias valvares, comparados com aqueles submetidos a outros procedimentos que não as valvas cardiacas. De acordo com os autores, este tipo de cirurgia está relacionado com a maior freqüência de comprometimento sistêmico ou reoperação, após um reparo valvar prévio ou uma substituição de valva. Cirurgias valvares são freqüentemente realizadas em pacientes com endocardite, muitos deles com cultura bacteriológica positiva do campo operatório.

As técnicas para fechamento da esternotomia mediana são diversas, variando entre as equipes, desde o tipo de fio a ser utilizado, até a técnica a ser empregada. O que determina a melhor é a experiência apresentada pela equipe, obedecendo um padrāo protocolar. SIRIVELLA et alii ${ }^{38}$ recomendam a utilizaçāo de fitas de Mersilene, com método de escolha para o fechamento em todos os pacientes que apresentam alto risco de deiscência, quando comparado com fio de aço.

A escolha da técnica deve ser cuidadosa, podendo o cirurgiāo lançar māo daquela que melhor se adaptar à qualidade do osso, ao peso do paciente e à forma como foi realizada a toracotomia.

No Instituto Dante Pazzanese de Cardiologia, o reforço unilateral ou bilateral do esterno com fios de aço passados nos espaços intercostais obedece rigorosamente essas variáveis, promovendo melhor sustentaçāo dos fios de aço, para fechamento da esternotomia (Figura 2).

Nos pacientes obesos e, principalmente, com aspecto osteoporótico do osso, utilizaram-se fios de aço $\mathrm{n}: 5$ e reforço bilateral do esterno. Atençāo deve ser dada à maneira pela qual é feita a toracotomia, pois, caso o esterno seja estreito e a incisăo apresentar uma borda maior que a oposta, poder-se-à estar diante de uma situação catastrófica para o paciente.

TABER \& MADARS ${ }^{41}$ propõem, como método preventivo da deiscência, a utilização de fios de aço ao redor da junção costocondral, em forma de oito. Este método é também utilizado para as esternotomias transversas.

Um método biomecânico foi proposto por LABITZKE et alii ${ }^{20}$, através da utilização de um sistema de roldanas. Esse sistema foi utilizado em 20 pacientes, alguns após tratamento convencional da deiscência de esterno com reosteosíntese, sem sucesso. A técnica apresentou meIhor estabilidade do esterno sem qualquer complicação. De acordo com os autores, essa base biomecânica pode ser aplicada rotineiramente, ou em casos especiais, evitando-se muitos problemas pós-operatórios.

A utilização de material sintético, na tentativa de prevenir a deiscência, também foi explorado por alguns autores.

NIKOL et alii ${ }^{28}$ utilizam hidroxiapatita na prevençāo da deiscência. Essa substância, de grande importância como componente dos ossos e dos dentes, muito utilizada entre os cirurgiōes dentistas, mostrou-se útil na prevenção da deiscência em pacientes de alto risco. Sua técnica fundamenta-se, basicamente, na interposição entre as duas bordas esternais, de corais de hidroxiapatita e posterior fechamento convencional do esterno com fios de aço.

NUGENT et alii ${ }^{29}$ apresentam uma técnica de fechamento com a utilizaçao de um flap de pericárdio, que reduz $\mathrm{a}$ incidência de mediastinite e de deiscência de esterno, comparada à de outros cirurgiōes de seu Serviço, que não utilizam esse procedimento. De acordo com Nugent e seu grupo, a incisão pericádica mediana é fácil e fornece excelente exposição para qualquer procedimento cardíaco. A desvantagem é que, freqüentemente, não é possivel reaproximar o pericárdio ao final da cirurgia, portanto, a superfície epicárdica do coração entra em contato direto com a superfície posterior do esterno. Uma vez que a infecção do esterno esteja estabelecida, a drenagem freqüentemente ocorre espontaneamente, através da incisão da esternotomia, resultando em contaminação do mediastino. Autores, baseiam-se na importância da vasculatura retroesternal, demonstrada pelo tratamento bem sucedido da mediastinite com rotação de um pedículo de omento para o mediastino anterior $^{3}$.

Alguns trabalhos mostram que vários métodos foram ineficazes para o fechamento das bordas esternais. SAN FELIPPO \& DANIELSON ${ }^{32}$ consideram que o fechamento da esternotomia mediana através da utilização de fitas de nylon mostrou-se inaceitável, devido ao grande número de complicações, como drenagem crônica, dor local, infecçōes e deiscência, comparado com a utilização de fios de aço.

Além das técnicas rotineiras propostas para o fechamento da esternotomia mediana nas situaçōes de deiscência, outras foram apresentadas para seu fechamento. A cirurgia deve ser indicada em uma fase na qual a infecção esteja o mais controlada possível, a fim de evitar complicaçōes pós-operatórias como sepsis. Após melhora nas culturas da ferida cirúrgica, os pacientes devem ser programados eletivamente para correção do defeito.

Nos pacientes que se encontram em franca mediastinite com ou sem sepsis, a cirurgia poderá trazer algum benefício, porém o momento da intervenção é duvidoso. É necessária reserva de sangue para este tipo de procedimento, pois a abordagem, nessa situaçăo crítica, pode ser perigosa, com riscos de acidente durante a abertura. 
MARQUES, R. L.; ARNONI, A. S.; DINKHUYSEN, J. J.; ABDULMASSIH NETO, C.; SOUZA, L. C. B.; PAULISTA, P. P. - ManUSeio da deiscência do esterno no pós-operatório de cirurgia cardiaca. Rev. Bras. Cir. Cardiovasc., 5(2): 125-136, 1990.

HARJULA \& JARVINEN ${ }^{13}$ propōem, para os pacientes com deiscência sem mediastinite, o desbridamento ósseo e dos demais tecidos, com fechamento primário do esterno.

BREYER et alii ${ }^{4}$ propõem, além da técnica de fechamento com fio de aço, a utilização de suturas com fios de Dacron.

HICKS et alii consideram que o sistema de fixação deve ser simples e eficiente. Após o diagnóstico da deiscência, o paciente é levado ao centro cirúrgico, desbridado todo o tecido ósseo, celular subcutâneo e pele, para retirada do material necrótico. Utilizam um sistema de compressão composto de duas hastes e um eixo central que, progressivamente, são aproximados em associação com fios de aço.

MILLER et $a_{i i}{ }^{24}$ concordam com o fato de que os fatores mecânicos tomam um papel importante na deiscência de esterno, enfatizando que a fixação do osso somente com fios de aço não é suficiente para suportar esses fatores antes da completa fusăo da esternotomia, principalmente em indivíduos obesos. Biomecanicamente, o sistema proposto por HICKS et alii ${ }^{15}$ é similar, porém, de acordo com MILLER et alii ${ }^{24}$, vem caindo em desuso. O sistema "Harrington", proposto por Miller, fornece um aspecto melhor que o de Hicks.

SOMMERHAUG et alii ${ }^{39}$ propōem, para tratamento da deiscência, a utilização de fios de aço pericostais em associação com fios de aço transesternais, promovendo maior estabilidade do esterno.

A abordagem cirúrgica dos pacientes com mediastinite, como complicação da deiscência de esterno, envolve, além do tratamento do osso e dos demais tecidos, a "toilette" mediastinal, seguida de acompanhamento pós-operatório rigoroso, principalmente nos pacientes idosos.

JOHNSON et alii ${ }^{16}$ propõem critérios para o fechamento primário sem irrigação contínua com antibióticos ou soluçāo de povidine a $0,5 \%$ evitando complicaçōes secundárias com os cateteres ou com as soluçōes. Os critérios são: tecido superficial sem coleção purulenta e, preferentemente, com tecido de granulação, ausência de drenagem de coleçōes purulentas e culturas negativas obtidas 24 horas antes do fechamento.

A utilização de irrigação mediastinal trouxe benefícios para doentes com grave infecção do mediastino. As soluçōes mais utilizadas são com antibióticos e a solução de povidine a $0,5 \%$ porém outras técnicas para o tratamento da mediastinite sem irrigação foram propostas. DURANDY et alii ${ }^{9}$ descrevem um método que não necessita de irrigação. Baseia-se na colocação de um ou dois cateteres multiperfurados nas áreas infectadas, conectados a um pequeno recipiente, onde uma pressão negativa ( $\pm 700 \mathrm{mmHg}$ ) é criada.
BRYANT et alii ${ }^{5}$, após identificada a infecção, abrem a incisão da esternotomia, com limpeza de todo o mediastino e lavagem com antibióticos. Após retirada de todo material necrótico, um ou dois cateteres plásticos (16 ou 18 F) são inseridos no mediastino para irrigação com solução de neomicina e bacitracina, infundindo-se por um período de 10 a 14 dias, seguido de remoção gradual dos cateteres. Para eliminação do líqüido de irrigação, utilizam um ou dois cateteres intercostais abaixo do apêndice xifóide, evitando extensão da infecção para a incisăo da cardiotomia e enxertos ou próteses valvares, o que seria fatal para o paciente.

VERKKALA \& JARVINEN ${ }^{44}$ utilizam, também, irrigação com antibióticos e providine a $0,5 \%$ em um volume de 2 a 3 litros/dia no espaço retro-esternal. Os antibióticos mais utilizados são a cloxacilina e cefamandole. $O$ balanço entre entrada e saída do fluido é necessário, a fim de prevenir uma irrigaçăo insuficiente. A irrigaçăo continua até que o fluido drenado esteja claro e com estudo bacteriológico negativo. Em seguida, o cateter de irrigação é retirado, porém o de drenagem permanece por um ou dois dias. Os autores, após a utilizaçāo de antibiótico e de povidine, concluem que a irrigaçâo com neomicina em concentraçóes elevadas produz efeitos tóxicos com insuficiência renal aguda, lesōes necróticas e morte.

THURER et alii ${ }^{42}$ utilizam irrigação contínua com povidine a $0,5 \%$, em adultos e crianças.

É importante observar que antibiótico especifico deve ser infundido via venosa, de acordo com a cultura e o antibiograma do líqüido drenado, como afirmam VERKKALA et alii ${ }^{44}$.

A utilização de qualquer fluido, para a irrigaçăo mediastinal, pode trazer, como conseqüência, efeitos tóxicos, comprometendo o estado pós-operatório desses pacientes. CAMPISTOL et alii ${ }^{6}$ citam como possíveis complicaçōes tóxicas com o uso de soluçāo de povidine: acidose metabólica refratária, hipernatremia severa, mudanças no estado mental, supressão da tireóide, febre e morte. Portanto, deve-se evitar o uso prolongado de soluçāo de povidine em pacientes com função renal comprometida, sendo contra-indicado o uso rotineiro nesses casos.

GLICK et alii ${ }^{12}$ observam que os sinais e sintomas da toxidade pelo povidine săo inespecíficos e esporádicos. Incluem, como complicaçốes, além das citadas no trabalho de Campistol, rash cutâneo, nódulos subcutâneos, náuseas, diarréia e falência hepática. Devido às complicaçōes apresentadas em seus pacientes, os autores contram-indcam a irrigação mediastinal com povidine.

KOPEL et alii ${ }^{19}$ tratam a infecção mediastinal com solução de gentamicina a $0,8 \%$. A monitorização das concentraçōes séricas de garamicina deve ser rigorosa, a fim de evitar complicaçōes como insuficiência renal. 
MARQUES, R. L.; ARNONI, A. S.; DINKHUYSEN, J. J.; ABDULMASSIH NETO, C.; SOUZA, L. C. B.; PAULISTA, P. P. - ManUSeio da deiscência do esterno no pós-operatório de cirurgia cardiaca. Rev. Bras. Cir. Cardiovasc., 5(2): 125-136, 1990.

Porém, com o uso criterioso, através da monitorização dessa substância em periodos curtos, os riscos diminuem significativamente.

A irrigação mediastinal, com soluçāo de neomicina a $0,25 \%$, foi utilizada por vários anos. CHEUNG et alii $^{7}$ utilizam este antibiótico.

O retalho miocutâneo serviu como método alternativo para casos de recidiva da infecção.

A interposição de musculatura peitoral ou abdominal na área deiscente trouxe melhor suporte circulatório, porém outras técnicas, com esta finalidade, foram propostas por vários autores. HEATH et alii ${ }^{14}$ consideram que a mobilização do omento gastro-epiplóico sobre a área deiscente em pacientes com mediastinite favorece a resolução desse tipo de infecção. Sua técnica baseia-se na mobilização do omento com seu pedículo vascular sobre o mediastino, ancorando-o em direção à veia inominada; em seguida, o esterno é fechado de maneira tradicional com fios de aço. De acordo com os autores, as vantagens da técnica são: deambulação precoce com melhora na função pulmonar, espaço morto vascularizado com tecido sadio e aspecto cosmético satisfatório. Uma desvantagem potencial é a reintervenção nesse tórax, devido a vascularização e adesão entre as estruturas do mediastino e o omento.

BERNARD et alii $^{3}$ também utilizam essa técnica, em seus pacientes, citando, como vantagens na sua utilização, vascularização e suprimento linfático, absorção ampla de fluidos e rica fonte de macrófagos.

Nos casos de necrose total de esterno, TIZIAN et alii ${ }^{43}$ propõem o uso de um flap do músculo latissimus dorsicom preservação do pedículo toracodorsal, posicionando-o entre o músculo grande peitoral e a parede torácica. A parte mais distal do flap muscular é suturada em três planos, obliterando o espaço morto.

SCULLY et alii ${ }^{35}$ comparam a irrigação com antibiótico e a mobilização da musculatura peitoral no tratamento das infecções profundas do esterno. Concluem que ambas as técnicas são igualmente efetivas no manuseio da mediastinite, após cirurgia cardiaca, porém recomendam desbridamento e fechamento do tórax com rotação do músculo peitoral. Outros trabalhos mostram que a técnica de rotação muscular oferece melhor resultado para os caso de mediastinite, na medida em que reduz a mortalidade, aumenta o sucesso de uma terapia primária e diminui o tempo de internação hospitalar ${ }^{25,31}$.
PAIROLERO \& ARNOLD ${ }^{31}$ tratam as deiscências de esterno recidivantes com desbriamento esternal, sendo que alguns de seus pacientes necessitam de ressecção esternal e reconstrução com utilização de flap muscular, transposição de omento, ou ambas. A ressecção esternal com rotação de omento ou com rotação de reto abdominal, para os casos de osteomielite crônica de esterno, também foi utilizada por LEE et alii ${ }^{21}$.

De acordo com STIEGEL et alii ${ }^{40}$, o tratamento da mediastinite, em crianças, com rotação de músculo grande peitoral, reto abdominal ou ambos, mostrou-se satisfatório, quando comparado com irrigação mediastinal. Para o autor, essa opção de tratamento oferece menor dependência de suporte ventilatório e significante diminuição do tempo de recuperação pós-operatória.

\section{CONCLUSÕES}

A deiscência da esternotomia mediana apresentou maior incidência nos pacientes que se submeteram a cirurgia de revascularização do miocárdio.

Dezesseis pacientes apresentaram deiscência de esterno, sendo que, em 14 deles, foi utilizada a artéria mamária como enxerto, surgerindo que a dissecção da artéria mamária é um fator de risco importante para esta complicação e, quando realizada em pacientes diabéticos, a incidência de deiscência esternal aumentou.

Nos pacientes que apresentaram deiscência sem mediastinite, as técnicas empregadas mostraram-se eficientes, com boa cicatrização da ferida operatória e meIhoria do quadro clínico.

Nos casos com mediastinite, os resultados não são tão satisfatórios. Em nossos cinco casos, ocorreram três óbitos, sendo que os outros dois pacientes necessitaram várias intervençōes para correção da complicação.

Acreditamos que a utilização de retalho miocutâneo do músculo grande peitoral ou do reto abdominal seja de grande importância nos casos de deiscência esternal sem mediastinite e que possa ajudar nos casos com mediastinite.

O reconhecimento precoce do problema e a reintervenção o mais breve possível auxiliam na prevenção das complicações infecciosas, evitando que o quadro de infecção mediastinal se instale e melhorando o prognóstico desta grave complicação. 
MARQUES, R. L.; ARNONI, A. S.; DINKHUYSEN, J. J.; ABDULMASSIH NETO, C.; SOUZA, L. C. B.; PAULISTA, P. P. - ManUSeio da deiscência do esterno no pós-operatório de cirurgia cardiaca. Rev. Bras. Cir. Cardiovasc., 5(2): 125-136, 1990.

RBCCV 44205-116

MARQUES, R. L.; ARNONI, A. S.; DINKHUYSEN, J. J.; ABDULMASSIH NETO, C.; SOUZA, L. C. B.; PAULISTA, P. P. - Management of sternum dehiscence in the postoperative period after cardiac surgery. Rev. Bras. Cir. Cardiovasc., 5(2): 125-136, 1990.

ABSTRACT: Ninety hundred and six patients with varied pathology $(43 \%$ coronarian, $37 \%$ valvular, $17 \%$ congenital and $3 \%$ others) between december 1987 and december 1989 , underwent cardiac surgery with cardiopulmonary bypass. In the intra-hospitalar postoperative period there were nineteen cases of partial or total dehiscence of median thoracotomy $(2 \%)$ which occurred, as an average, within the first week, being reoperated within a third week. In all cases, wound cultures showed predominance of gram positive bacteria and in few of them gram negative bacteria or fungii were found. There was only one case in which no infective agent was isolated. In this patient group, the existance of pre-disponent factors were observed, such as diabetes mellitus, obesity, chronic obstructive pulmonary disease and prolonged surgery time (average: beyond six hours). There was predominance of adult patients whose ages varied from forty to sixty seven years, with median age of fifty three years $(89 \%)$. In $84 \%$ of the patients, internal mammary artery dissection had been carried out, to be used as vascular graft in surgical revascularization of the miocardium. Other than general therapeutic measures like local and specific systemic antibiotic therapy (to sterelize the infected wound), patients were taken to surgery proceeding with cleansing and debridement of surgical planes including the sternum, leaving in some cases continuous irrigation with povidine-iodine solution. A miocutaneous flap was rotated in two patients who were refractive to treatment. Of five cases with mediastinitis, three died because of multiple organ failure and sepsis. The remaining group presented favorable evolution and were discharged three weeks after surgical reoperation with appropriate consolidation of the surgical wound.

DESCRIPTORS: sternum dehiscence, surgery.

\section{REFERÊNCIAS BIBLIOGRÁFICAS}

1 ARNOLD, M. - The surgical anatomy of sternal blood suply. J. Thorac. Cardiovasc. Surg., 64: 596-608, 1972.

2 ARNOLD, P. G. \& PAIROLERO, P. C. - Chest wall reconstruction: experience with 100 consecutive patients. Ann. Surg., 100: 725-731, 1984.

3 BERNARD, J. P.; SCHANDI, F.; KEON, W. J. - Omental pedicle grafting in he treatment of poststernotomy mediastinitis. Canadian J. S., 32: 328-330, 1989.

4 BREYER, R. H.; MILLS, S. A.; HADSPETH, A. S.; JOHNSTON, F. R.; CORDELL, A. R. - A prospective study of sternal wound complications. Ann. Thorac. Surg., 5: 412-416, 1984.

5 BRYANT, L. R.; SPENCER, F. C.; TRINKLE, J. K. - Treatment of median sternotomy infeccion by mediastinal irrigation with an antibiotic solution. Ann. Surg., 169: 914-920, 1969.

6 CAMPISTOL, J. M.; ABAD, C.; NOGUE, S.; BERTRAN, A. - Acute renal failure in a patient treated by continuous povidone-iodine mediastinal irrigation. J. Cardiovasc. Surg., 29: 410-412, 1988.

- CHEUNG, E. H.; CRAVER, J. M.; JONES, E. L.; MURPHY, D. A.; HATCHER, C. R.; GUYTON, R. A. - Mediastinitis after cardiac valve operations: impact upon survival. J. Thorac. Surg., 90: 517-522, 1985.

8 COOLEY, D. A. - Discussion. In: SCULLY, H. E. et alii, Referência 35.
9 DURANDY, Y.; BATISSE, A.; BOUREL, P.; DIBIE, A.; LEMOINE, G.; LECOMPTE, Y. - Mediastinal infection after cardiac operation: a simple closed technique. J. Thorac. Cardiovasc. Surg., 97: 282-285, 1989.

10 ENGELMAM, R. M.; WILLIAMS, C. D.; GOUGE, T. H. Mediastinitis following open-heart surgery. Arch. Surg., 68: 962-968, 1974.

11 FERNANDO, B.; MUSZYNKSKI, C.; MUSTOE, T. - Closure of a sternal defect with the rectus abdominis muscle after sacrifice of both internal mammary arteries. Ann. Plastic Surg., 21: 468-471, 1988.

12 GLICK, P. L.; GUGLIELMO, J.; TRAMBAUGH, R. F.; TUR LEY, K. - lodine toxicity in a patient treated by continuous povidone-iodine mediastinal irrigation. Ann. Thorac. Surg., 39: 478-480, 1984.

13 HARJULA, A. \& JARVINEN, A. - Postoperative median sternotomy dehiscence. Scand. J. Thorac. Cardiovasc. Surg., 17: 277-281, 1983.

14 HEATH, B. J.; BAgNATO, V. J.; MISS, J. - Poststernotomy mediastinitis treated by omental transfer without postoperative irrigation or drainage. J. Thorac. Cardiovasc. Surg., 94: 355-360, 1987.

15 HICKS, G. L.; HAAKE, W.; STEWART, S. S.; DE WEESE J. A. - The nuts and bolts of sternal dehiscence. Thorac. Surg., 36: 364-366, 1982.

16 JOHNSON, J. A.; GALL, W. E.; GUNDERSEN, E.; COGBILL, T. H. - Delayed primary closure after sternal wound infection. Ann. Thorac. Surg., 47: 270-273, 1989. 
MARQUES, R. L.; ARNONI, A. S.; DINKHUYSEN, J. J.; ABDULMASSIH NETO, C.; SOUZA, L. C. B.; PAULISTA, P. P. - ManUSeio da deiscência do esterno no pós-operatório de cirurgia cardiaca. Rev. Bras. Cir. Cardiovasc., 5(2): 125-136, 1990.

17 JULIAN, O. C.; LOPEZ BELLO, M.; DYE, W. S.; JAVID, H.; GROVE, W. J. - The median sternal incision in intracardiac surgery with extracorporeal circulation. Surgery, 42: 753-761, 1957.

18 JURKIEWICZ, M. J.; BOSTWICK, J. L.; HESTER, T. R.; BISHOP, J. B.; CRANER, J. - Infected median sternotomy wounds: succesful treatment by muscle flaps. Ann. Surg., 191: 738-743, 1980.

19 KOPEL, M. E.; RIEMERSMA, L.; FINLAYSON, D. C.; TOBIA, V.; JONES, E. L.: HALL, R. I.; MULLINS, R.; LAMPASONA, V. - Gentamicin solution for mediastinal irrigation: systemic absorption, bactericidal activity, and toxocity. Ann. Thorac. Surg., 48: 228-231, 1989.

20 LABITZKE, R.; SCHRAMM, G.; WITZEL, U.; QUISTHOUT, P. - "Sleeve-rope closure" of the median sternotomy after open heart operation. Thorac. Cardiovasc. Surg., 31: 127-128, 1983.

21 LEE, A. B.; SCHSCHIMERT, G.; SHATIN, S. - Total excision of the sternum and thoracic pedicle transposition of the greater omentum. Surgery, 80: 433-434, 1976.

LOOP, F. D.; LYTLE, B. W.; COSGROVE, D. M.; MAHFOOD, S.; HENRY, M. C.; GOORMASTIC, M.; STEWART, R. W.; GOLDING, L. A. R.; TAYLOR, P. C. - Sternal wound complications after isolated coronary artery bypass grafting: early and late mortality, morbidity, and cost of care. Ann. Thorac. Surg., 49: 179-187, 1990.

23 MILLER, M. D.; JOHNSON, R. G.; NAIFEH, J. - Repair of sternal dehiscence using Harrington compression system. Ann. Thorac. Surg., 45: 684-685, 1988.

24 MILLER, J. I. \& NAHAI, F. - Repair of the dehisced median sternotomy incision. Surg. Clin. N. Am., 69: 1091-1103, 1989.

25 NAHAI, F.; RAND, R. P.; HESTER, R.; BOSTWICK, J.; JURKIEWICZ, M. J. - Primary treatment of the infected sternotomy wound with muscle flaps: a review of 211 consecutive cases. Plastic Reconst. Surg., 84: 434-441, 1988.

26 NEALE, H. W.; KREILEIN, J. G.; SCHREIBER, J. T.; GREGORY, R. O. - Complete sternectomy for chronic osteomyelitis with reconstruction using a rectus abdominis myocutaneous island flap. Ann. Plast. Surg., 6: $305-314,1981$.

27 NEWMAN, L. S.; SZCZUKOWSKI, L. C.; BAIN, R. P.; PERLINO, C. A. - Suppurative mediastinitis after open heart surgery: a case control study of risk factors. Chest, 94: 546-553, 1988.

28 NIKOL, S.; MINALE, C.; MESSMER, B. - Interposition of coral between sternal blades to prevent postoperative dehiscence: a new method. Ann. Thorac Surg., 45: 694-696, 1988.

29 NUGENT, W. C.; MAISLEN, E. L.; CONNOR, G. T.; MARRIN, C. A. S.; PLUME, S. K. - Pericardial flap prevents

sternal wound complications. Arch. Surg., 123: 636-639, 1988.

30

OTTINO, G.; DE PAULIS, R.; PANSINI, S.; ROCCA, G. TALLONE, V.; COMOGLIO, C.; COSTA, P.; ORZAN, F.; MOREA, M. - Major sternal wound infection after open-heart surgery: a multivariate analysis of risk factors in 2579 consecutive operative procedures. Ann. Thorac. Surg., 44: 173-179, 1987.

PAIROLERO, P. C. \& ARNOLD, P. G. - Management of recalcitrant median sternotomy wounds. J. Thorac. Cardiovas. Surg., 88: 357-364, 1984.

SAN FELIPPO, P. M. \& DANIELSON, G. K. - Nylon bands for closure of median sternotomy incisions. Ann. Thorac. Surg., 13: 404-407, 1972.

SARR, M. G.; GOTT, V. L.; TOWNSEND, T. R. - Mediastinal infection after cardiac surgery. Ann. Thorac. Surg., 38: 415-421, 1984.

SCHUMAKER, H. B. \& MANDELBAUM, I. - Continuous antibiotic irrigation in the treatment of infection. Arch. Surg., 86: 384-386, 1963.

SCULLY, H. E.; LECLERC, Y.; MARTIN, R. D.; TONG, C. P.; GOLDMAN, B. S.; WEISEL, R. D.; MICKLEBOROUGH, L. L.; BAIRD, R. J. - Comparison between antibiotic irrigation and mobilization of pectoral muscle flaps in treatment of deep sternal infections. J. Tho rac. Cardiovasc. Surg., 90: 523-531, 1985.

SERRY, C.; BLECK, P. C.; JAVID, H.; HUNTER, J. A.; GOLDIN, M. D.; DE LARIA, G. A. NAJAFI, H. - Sternal wound complications. J. Thorac. Cardiovasc. Surg., $80: 861-867,1980$.

37 SHAFIR, R.; WEISS, J.; HERMAN, O.; COHEN, N.; STERN, D.; IGRA, I. - Faulty sternotomy and complications after median sternotomy. J. Thorac. Cardiovasc. Surg., 96: 310-313, 1988.

SIRIVELLA, S.; ZIKRIA, E. A.; FORD, W. B.; SAMADANI, S. R.; MILLER, W. H.; SULLIVAN, M. E. - Improved technique for closure of median sternotomy incision. J. Thorac. Cardiovasc. Surg., 94: 591-595, 1987.

39 SOMMERHAUG, R. G.; REID, D. A.; WOLFE, S. F.; LIND SEY, D. E. - Sternal dehiscence: pericostal guy wires equals sternal stability. Ann. Thorac. Surg., 42 : 107-108, 1986.

40 STIEGEL, R. M.; BEASLEY, M. E.; SINK, J. D.; HESTER, T. R.; GUYTON, R. A.; PERRELLA, A. M.; WILLIANS W. H. - Management of postoperative mediastinitis in infants and children by muscle flap rotation. $A n n$. Thorac. Surg., 46: 45-46, 1988.

41 TABER, R. E. \& MADARS, J. - Prevention of sternotomy wound disruptions by use of figures of eight pericostal sutures. Ann. Thorac. Surg., 8: 367-369, 1969.

42 THURER, R. J.; BOGNOLO, D.; VARGAS, A.; ISCH, J. H.; KAISER, G. A. - The management of mediastinal 
MARQUES, R. L.; ARNONI, A. S.; DINKHUYSEN, J. J.; ABDULMASSIH NETO, C.; SOUZA, L. C. B.; PAULISTA, P. P. - ManUSeio da deiscência do esterno no pós-operatório de cirurgia cardiaca. Rev. Bras. Cir. Cardiovasc., 5(2): 125-136, 1990.

infection following cardiac surgery: an experience utilizing continuous irrigation with povidone-iodine. $J$. Thorac. Cardiovasc. Surg., 68: 962-968, 1974.

43 TIZIAN, C.; BORST, H. G.; BERGER, A. - Treatment of total sternal necrosis using the latissimus dorsi muscle flap. Plast. Reconst. Surg., 76: 703-707, 1985.
44 VERKKALA, K. \& JARVINEN, A. - Mediastinal infection following open heart surgery: treatment with retrosternal irrigation. Scand. J. Thorac. Cardiovasc. Surg., 20: 203-207, 1986.

45 WRAY, T. M.; BRYANT, R. E.; KILLEN, D. A. - Sternal osteomyelitis and costochondritis after median sternotomy. J. Thorac. Cardiovasc. Surg., 65: 227-233, 1973. 